\title{
Complex Classification of Second Language Motivation in English Language Learning: A Typological-Historical Critical Review
}

\author{
* Dr. Muhammad Ishtiaq (Corresponding Author) \\ ** Dr. Muhammad Sabboor Hussain \\ **** Hussain Ahmed
}

\begin{abstract}
This theoretical paper aims to describe the complex nature of second language learning motivation, focusing on its types and history. Motivation is the process that accounts for a person's intensity, direction, and persistence of effort towards a goal-achievement. It is an essential phenomenon in almost every field of knowledge, including psychology, sociology, and education, to name a few. Several studies have been conducted on the role and rank of motivation in different contexts and knowledge fields. A large body of literature has also tried to relate motivation with a variety of variables. When it comes to second language learning, the vital role of motivation is indisputable. However, the more it is investigated, the more complex this construct comes to the surface. During the past few decades, its typological-historical critical review reveals that its fast-evolving phases have added to its complexity and importance at the same time. The paper concludes that motivation will remain a complex construct; however, more in-depth, comprehensive, and serious investigations may help us understand this phenomenon. This paper has opened some curious questions which demand further field investigation and research probing.
\end{abstract}

Keywords: Motivation Complexity, Historical Review of Motivation, Typological Review of Motivation, Second Language Learning, Types of Motivation

\section{Introduction}

It is desirable to discuss a brief background of the term motivation to understand it as a critical construct in second language learning/teaching. The word motivation originates from the Latin word movere, which means move. It is a process that initiates, guides, and maintains goal-oriented behaviors. It is an internal condition directed to bring a change, either in the self of humans or their environment. Motivation endows an individual with the drive and direction needed to engage in an activity or a task. It causes an individual to act in a particular situation in a particular way to reach a goal or complete a task. Second language learning motivation, in particular, requires to understand this construct in its totality.

Motivation is a multi-layered phenomenon spreading over the whole human existence. It involves emotional, social, and cognitive forces and factors that activate knowledge, skills, and attitude/aptitude (KSA) in humans. In an ordinary sense, this term is recurrently used to describe why, when, and how a person does something. It is the driving force that pushes or pulls humans to specific actions- good or bad. When short-term motivation turns into a long-term one, it not only refers to the factors that activate behaviors; it also involves the aspects that direct and maintains goal-directed actions. As a result, we often infer when, why, and how people do what they do, based on the observable behavior patterns in their actions, reactions, and interactions. Language is the chief feature of human existence, which starts with birth and continues till the end.

Second language learning motivation is an old and vital area of research. There is a general belief among researchers that motivation plays a vital role in all kinds of learning. Likewise, many existing studies in the literature of different disciplines have examined different motivation variables and their

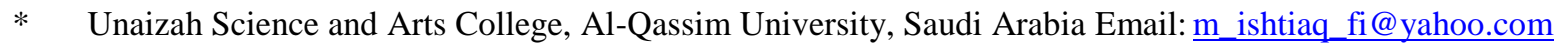

** GC Women University, Sialkot, Pakistan Email: saboor.hussain@gcwus.edu.pk

*** English Language Institute, King Abdul Aziz University, Saudi Arabia Email: hahmad.me@gmail.com 
effects on second language learning. However, the results are inconsistent in different contexts. The same variables that have positive effects in one context prove to be detrimental in some others. This bewildering scenario is probably due to the complex nature of second language learning motivation, which needs to be defined, explained, and explored at length.

When it comes to defining motivation, many definitions have been put forward in different studies. According to Piaget's cognitive developmental theory, motivation can best be comprehended as 'a built-in unconscious striving towards more complex and differentiated development of the individual's mental structures' (Oxford \& Shearin, 1994, as cited in Keblawi, 2009). Thus defined, it becomes a twodimensional phenomenon that goes to internal and external facets in human minds. Järvelä, Volet, and Järvenoja (2010) focus more on the external dimension and define motivation as the driving force that leads to involvement and, ultimately, achievement. In the same sense, according to Tohidi and Jabbari (2012), motivation is the force that causes movement in humans. The debate on definitions is neverending as new ones keep emerging from time to time.

The debate about motivation has gained new prominence with several recent studies. The researchers have attempted to explain and explore the historical perspective of motivation. However, the topic is too large, and researchers have struggled to investigate the concept while focusing only on some of its aspects. For example, Gollwitzer, Oettingen (2015) tried to relate the history of motivation with goal orientation, whereas Pakdel (2013) tried to explain the concept with motivation theories. The current study explains how motivation evolved through different phases of history and how this evolution impacted its classification, making it a complex but interesting area of study and research.

\section{The Complexity of Second Language Motivation}

Some researchers have discussed the complexity of motivation as a critical construct in research, knowledge, and education. Kreishan and Al-Dhaimat (2013) state that motivation is a complex construct, and it cannot be studied unless viewed through different components. These components can be further studied to establish their link with motivation and their effects on second language learning. Gardner (2012) argues that researchers have tried to relate motivation to several variables like the classroom environment, interest, satisfaction, self-confidence, gender, and age. Several other variables were linked to motivation by some other researchers. Zhou (2012) contends that motivation affects learners' autonomy, effort, persistence, attention, achievement, and language learning strategies.

A considerable amount of literature suggests that traditionally motivation has been associated with different fields of research. Keblawi (2009) argues that motivation includes social, educational, and cognitive psychology and incorporates the social, educational, and sociolinguistic theories that should be taken into account for comprehending this complex construct. Some researchers have also divided motivation into different components to understand its different aspects. Gardner (2007) believes that we can study motivation with the help of three components - cognitive, affective, and behavioral. However, each of these components has further been divided into different variables. Thus, it is difficult for researchers to investigate all these variables while studying motivation.

Another aspect that makes second language learning motivation a complex construct is its investigation in educational and cultural contexts. Gardner (2007) argues that if we want to reach the roots of second language learning motivation, we should relate it to its educational and cultural contexts. He further adds that educational and cultural contexts are essential in studying motivation because learners' attitude is key to the learning situation, and their integrative orientation influences their motivation. Therefore, while taking into account the educational context, one must focus on the classroom atmosphere. The classroom atmosphere factors include the KSA (Knowledge, Skills, Attitude/Aptitude) of the teacher and the taught the program's quality and appropriateness of the curriculum and the learning material.

Learning a second or a foreign language varies considerably from other subjects as learning other subjects do not require learners to learn about others' cultures. Learners from different cultures may have different attitudes towards learning a second or foreign language. As an example, it is believed in North America that Europeans are better at language learning than North Americans. This belief may or may not be accurate; however, it may affect North Americans' language learning attitudes (Gardner, 2007). Hence, 
it can be said that what is motivating for an American or a European learner may not be the same for a Saudi or a Pakistani learner. Kreishan and Al-Dhaimat (2013) critically reviewed different studies (Dodick, 1996; Richard-Armato, 1998; Coleman, 1995; Svans, 1987) and concluded that cultures differ in nature and react differently towards the target language. It is, therefore, essential to study motivation considering the educational and cultural contexts of that population. The researchers working in this domain need to be mindful of all the factors, as mentioned above.

Another aspect of motivation that makes it challenging and complex to study is its dynamic nature. According to Zheng (2012), motivation does not remain constant, as, with the rise and fall of motivation, learners' effort and performance also fluctuate. In the last phase of motivation, the complex dynamic system came as a solution that suggested a holistic approach compared to the previously advocated segregated approaches. However, with the emergence of a complex dynamic system, some new issues have also appeared, such as which L2 motivation factors should be included and excluded from the study to conceptualize it (Dörnyei \& Ushioda, 2013). Therefore, awareness about the types of motivation is vital for a successful teaching-learning process.

\section{Types of Motivation}

Researchers have long been trying to study motivation by dividing it into different types or looking at its different elements. Gardner and Lambert (1959) divided motivation, which they termed as orientation, into integrative and instrumental motivation (as cited in Babaee, 2012). Dornyei (2005) divides instrumental motivation into two types based on Higgins' (1998) distinction: promotional instrumentality and preventive instrumentality. Promotional instrumentality promises productive outcomes, such as the hopes of becoming professionally and personally successful due to learning the L2 efficiently and proficiently. Preventive instrumentality prevents adverse outcomes associated with the duties and obligations that individuals have towards others.

Gardner (2007) came up with another distinction and divided motivation into language learning motivation and classroom learning motivation. The former refers to learning a second language, whereas classroom learning motivation refers to the motivation found in a language classroom. Gardner (2007) continues that language learning motivation is more stable as compared to classroom learning motivation. Several factors influence classroom learning motivation, such as the class atmosphere, the teacher, the course content, the learning material, and the facilities available to carry out teaching/learning effectively.

Deci and Ryan (1985) were probably the first ones to distinguish between intrinsic and extrinsic motivation. Intrinsic motivation is from one's inner mind to achieve something for pleasure and satisfaction gained in completing a task, whereas extrinsic motivation is for some separable outcomes, such as achieving good grades (Dörnyei \& Ushioda, 2013). Later, researchers, for example, Law (2011), also believe that intrinsic and extrinsic are two distinct types of motivation.

\section{Intrinsic Motivation}

According to Gardner et al. (2004), intrinsic motivation is an inner desire, such as learning a second language for genuine interest in the target language, culture, or enjoyment in learning (as cited in Sabet, Zafarghandi, \& Veisy, 2015). There seems to be no reward for intrinsic motivation. Law (2011) argues that students with high intrinsic motivation also gain satisfaction from being involved in an activity. Students with intrinsic motivation have high autonomy, relatedness, competence, and a sense of control (Kreishan \& Al-Dhaimat, 2013).

Intrinsic motivation refers to enjoyment, interest, or engagement in a task. Intrinsic motivation is within the individuals. It is associated with a person's identity and sense of well-being $(\mathrm{Ng} \& \mathrm{Ng}, 2015)$. Teaching such EFL learners who are intrinsically motivated will be more comfortable than those who are not. $\mathrm{Ng}$ and $\mathrm{Ng}$ (2015) present three types of intrinsic motivation: knowledge, accomplishment, and stimulation. Knowledge refers to motivation for learning L2; accomplishment means attempting to master a task, and stimulation refers to the motivation needed to perform a task.

\section{Extrinsic Motivation}

Extrinsic motivation is caused by an external reward, outcome, or consequence. $\mathrm{Ng}$ and $\mathrm{Ng}(2015)$ believe that extrinsic motivation is because of external award or praise; when learners think it is necessary to learn to achieve that award or praise. It means teachers can play an essential role in enhancing extrinsic 
motivation since they can use awards or praise to motivate their learners to learn. In other words, extrinsic motivation may lead to intrinsic motivation. Higgins (1998) divides extrinsic motivation into two typesone required to pursue success and the other needed to avoid failure (as cited in Kozaki \& Ross, 2011).

Deci and Ryan (1985) discuss different types of extrinsic motivation in Organismic Integration Theory (OIT) - a sub-theory of Self-Determination Theory (SDT), and the factors that promote or hinder internalization and integration. In SDT, internalization is considered a continuum from 'motivation' to passive compliance to active commitment. See Figure 1 for types of extrinsic motivation.

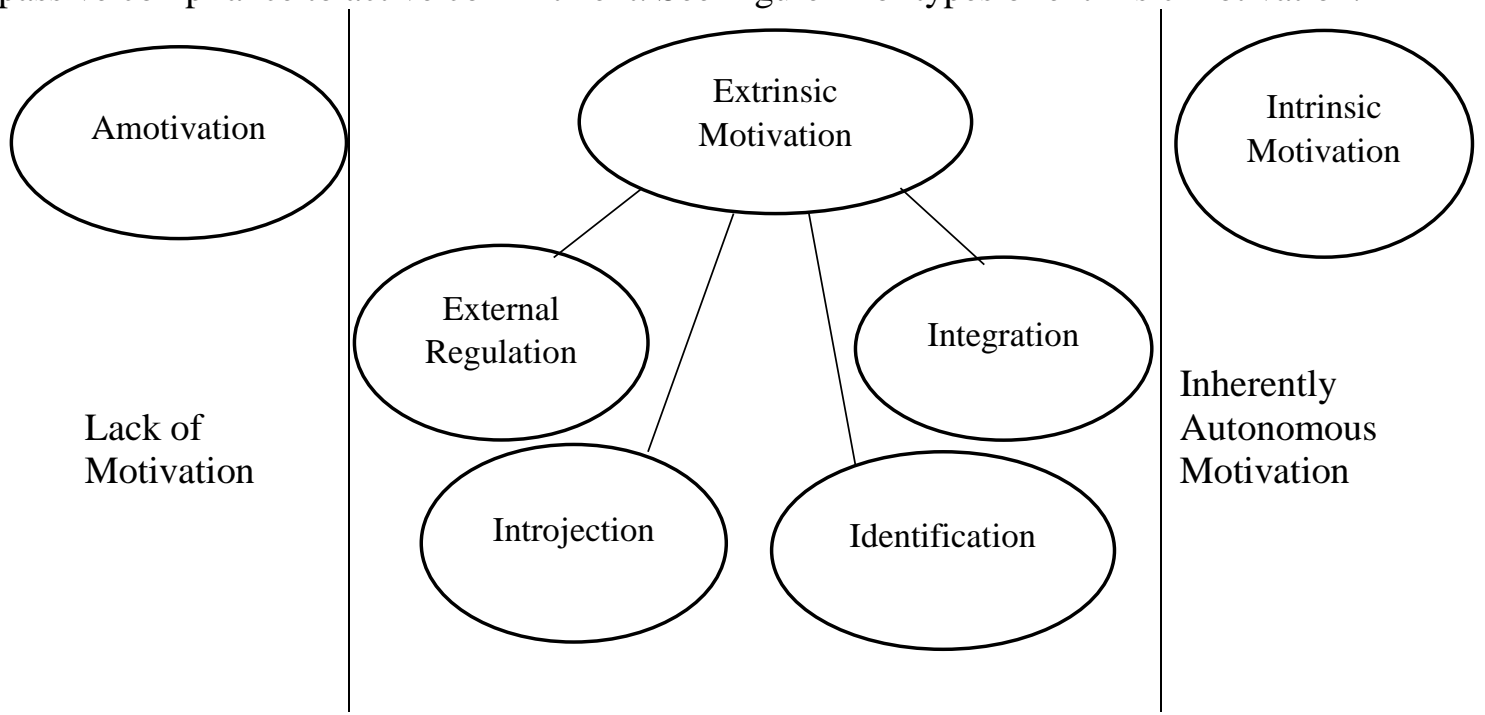

Figure 1: Types of Extrinsic Motivation (Source: Ryan and Deci, 2000)

At the far left, there is motivation. It is a state of lacking interest or intention to do something. To the right of motivation is the least form of extrinsic motivation called external regulation. It is a type of behavior to satisfy external demands or to obtain external rewards. To the right of this type of motivation is introjected regulation. This behavior is performed to avoid guilt or anxiety (Ryan \& Deci, 2000). To the right of it comes identification. It refers to a more autonomous type of self-determination. In this type of behavior, learners identify the importance of a task; thus, they learn something because they know its value (Ryan \& Deci, 2000).

To further right comes the most autonomous form of extrinsic motivation-integrated regulation. In this type of regulation, a person is more self-determined and assimilates the values of other things concerning himself (Ryan \& Deci, 2000). To the extreme right is intrinsic motivation. It can be declared as the most self-determined type of motivation. It suggests a continuum, and one does not have to pass through all these stages to be intrinsically motivated. If an activity motivates learners extrinsically, they may see its value and become intrinsically motivated, resulting in an orientation shift (Ryan \& Deci, 2000).

\section{Motivation from Past to Present: A Typological-Historical Perspective}

Motivation has evolved through different phases of history. In the past few decades, motivation has kept on moving from one transitional phase to another. During these transitional phases, several theories and models have been proposed by motivation researchers, which adds to its complexity. As Dornyei (1996) contends, the problem with the motivation construct is not its lack of theories but rather an abundance of theories and models related to it (as cited in Keblawi, 2009). According to Dörnyei and Ushioda (2013), there are four distinct phases of motivation.

a. The Social-Psychological Phase

b. The Cognitive-Situated Phase

c. Process-Oriented Phase

d. The Socio-Dynamic Phase 


\section{a. The Social-Psychological Phase}

The first phase in the history of motivation is the social-psychological phase. According to Dörnyei (2003), social psychologists were the first to investigate language learning motivation as they were aware of the social and cultural effects of L2 learning. This phase, which started in 1959 and continued until 1990, was dominated by social factors in psychology and L2 language acquisition (Brander, 2013). According to Dörnyei and Ushioda (2013), Gardner and Lambert (1959), for the first time, suggested that motivation plays an essential role in learning L2. Perhaps this was the time when the importance of motivation for language learning was recognized. Babaee (2012) argues that Gardner and Lambert (1959) differentiated motivation from orientation. By orientation, they meant the purpose behind learning a second language. This purpose/orientation can be integrative or instrumental. Integrative orientation refers to learning an L2 to communicate with native speakers, and instrumental orientation means learning a language to get some benefits of L2, like, for example, getting a job. Gardner (2007) refers to integrative orientation as openness to cultural identification.

Ever since the inception of the integrative and instrumental orientation of motivation, one's superiority over the other has been questioned. There has been a lack of agreement among the researchers. According to Babaee (2012), Gardner and Lambert (1959) considered integrative orientation superior to instrumental orientation in SLA. The study conducted by Ishtiaq, Ali, and Salem (2015) concluded that the students' integrative motivation was higher than the instrumental motivation on the pre-questionnaire on a five-point Likert scale. However, some previous studies (Lamb, 2007; Rahman, 2005) have concluded that instrumental orientation seems to have a higher value, though the importance of integrative orientation cannot be denied. However, the researchers are not in agreement with each other on the superiority of one type of motivation or even orientation over the other, although initially, people took integrative orientation as the predictor of successful ESL learning (Gardner \& Lambert, 1972, as cited in Dörnyei \& Ushioda, 2013).

The social-psychological phase saw motivation as a multidimensional construct. Gardner and Lambert (1959) included many factors in their study, such as orientation-index, the reason for learning L2, and attitudinal scale. However, the most crucial factor they discussed was the students' achievement level (Brander, 2013). Language learning motivation was distinguished from other types of learning motivation because L2 learners not only learn a new language they also try to get acquainted with the L2 community so much so that they try to adopt their lifestyle (Gardner \& Lambert 1972, as cited in Dörnyei \& Ushioda, 2013). Thus, exhibiting diverse characteristics, motivation becomes a complex phenomenon.

During this period, motivation was viewed as a social psychological phenomenon. Clément (1986) investigated Gardner and Lambert's ideas and claimed that proficiency, attitude, and motivation are indirectly linked (as cited in Brander, 2013). Numerous aspects of language learning motivation were investigated during this phase, and as a result, several new variables arose. Keblawi (2009) argues that ever since psychological concepts like anxiety, achievement needs, and locus of control have entered the domain of knowledge, researchers have started paying attention to individual differences in humans. He further stated that some models were proposed during this phase, such as Krashen's (1981) Monitor Model and Schuman's (1986) Acculturation Model.

\section{b. $\quad$ The Cognitive-Situated Phase}

After the social-psychological phase, motivation entered a new phase - the cognitive situated phase. This phase was not a rejection of the Social Psychological Phase; it was just a shift of focus (Dörnyei \& Ushioda, 2013), and this shift paved the way for studying other areas of L2 motivation. Guerrero (2015) contends that L2 motivation shifted from a general to a more specific perspective in this phase. This phase saw two significant trends; (i) a trend to bring motivation closer to cognitive theories and (ii) a trend to see motivation in a specific setting, for example, in a classroom instead of a general attitude towards L2 (Ushioda, 2012). Thus, the cognitive-situated phase brought motivation to the classroom setting, focusing more on learners' cognition and learning processes. The cognitive-situated phase was a transitional phase in the history of L2 motivation.

During the cognitive-situated phase, Dörnyei (1994) presented his famous motivation model. Dörnyei (1994) took up Crookes and Schmidt's (1991) model and presented a comprehensive model of L2 
motivation (as cited in Dörnyei \& Ushioda, 2013). This model has three levels, viz., Language, Learner, and Learning Situation. The first two levels have been taken from Gardner and Clément's theories supplemented by Dornyei's (1990) findings, whereas the third one mainly drew from educational psychology. The language level has many components related to the aspects of L2, such as integration and instrumentation. The learner level comprises individual characteristics such as self-confidence and self-efficacy, and the learning situation level involves situation-specific aims such as interest in the course, goal orientedness, goal cohesiveness, and goal structure (Dörnyei \& Ushioda, 2013). Table 2.1 shows Dornyei's (1994) framework of L2 motivation.

Table0 2.1

Dornyei's (1994) framework of L2 motivation

\begin{tabular}{ll}
\hline Language Level & Integrative motivational subsystem \\
& Instrumental motivational subsystem \\
\hline Learner Level & Need for achievement \\
& Self-confidence \\
& Self-efficacy \\
\hline Learning Situation Level & Interest in the course \\
& Goal-orientedness \\
& Group cohesiveness \\
& Classroom goal structure (cooperative, \\
& Competitive or individualistic \\
\hline
\end{tabular}

Source: Dornyei (1994)

\section{c. Process-Oriented Phase}

When the cognitive-situated period was over, a new era dawned when the process-oriented phase emerged. Otto and Dornyei (1998) devised a new model of L2 motivation, which included different aspects of motivation, motivation to start a task, motivation during the task, and afterward evaluation (Öztürk, 2012). The role of motivation was seen more closely in the completion of activities. Attempts were made to change the macro-level approach to the micro-level, focusing more on specific situations where motivation affects the actual L2 classrooms (Dörnyei, Henry, \& MacIntyre, 2014). The whole process of learning came under the researchers' consideration.

It was perhaps the first-time motivation was considered a dynamic phenomenon and not a static concept. The process-oriented motivation model suggests three phases; the pre-actional, the actional, and post-actional phases (Colak, 2008). In the pre-actional phase, motivation is generated to help learners choose a task and moves them into action (Öztürk, 2012). In the actional phase, executive motivation energizes the learners and helps them continue the task (Dörnyei \& Ushioda, 2013). The post-actional phase involves motivational retrospection when learners evaluate how they carried out the action and, in the future, what sort of tasks they would be motivated to start (Colak, 2008). Attempts were made to investigate motivation as a process and not as a fixed phenomenon.

Many researchers welcomed the process model of motivation; however, it also faced some criticism. According to Ushioda (2012), Dornyei and Otto's (1998) model is very comprehensive. However, at the same time, it has two shortcomings: (i) it presupposes the beginning and ending of a learning process, (ii) it presupposes that learning works in isolation without the interference of other actional processes. However, this phase attracted many L2 researchers because of its thorough investigation of motivation.

\section{d. Socio-Dynamic Phase}

Socio-Dynamic Phase has three very prominent approaches (Dörnyei \& Ushioda, 2013): i) when a person/learner is seen in context relational perspective of motivation (Ushioda, 2009), ii) when the L2 learner's motivational self-system is under study (Dornyei, 2005), and iii) when motivation forms complex dynamic systems in individuals (Dörnyei, 2009).

In 'A person in context relational view of motivation,' the researchers tried to see a person in a real-life situation. An individual should be seen in multiple contexts in which he/she lives and interacts (Dörnyei \& Ushioda, 2013). In this phase, an attempt was made to link motivation with the individual's 
environment. According to Ushioda (2009), a person cannot be separated from his/her moves, aspirations, and social relations. Therefore, researchers should focus on his/her behavior concerning all these factors. The best way to understand the learners' motivation is to observe their conversations with their teachers and classmates instead of giving them some structure to practice. This strategy was an attempt to shift motivation from the classroom to an individual's efforts.

The L2 motivational self-system was proposed by Dornyei (2005). It was derived from previous psychological theories, but its primary source was previous research in the second language (Dörnyei \& Ushioda, 2013). This system comprises three main components: ideal L2 self, ought to L2 self, and L2 learning experience (Dornyei, 2005). According to Dornyei (2005), the ideal L2 self is what learners want to do in the future. If they want to interact with native English speakers, they will improve their L2 to communicate well and achieve their ideals (Papi, 2010). According to Taguchi, Magid, and Papi (2009), the ideal L2 self is the same as integrativeness. Ought to L2 self is what learners feel they must do under their teachers' or parents' obligations (Papi, 2010). Ought to L2 self is, in fact, an external stimulus. As Noels (2003) points out, ought to L2 self is similar to extrinsic motivation.

L2 Learning Experience in Dornyei's L2 motivation self-system is the learners' experience of learning an L2 (Papi, 2010). Dörnyei (2009) asserts that motivation to learn a language does not come from an internal or external factor but the actual learning experience. If learners' experience in learning a language is enjoyable and motivating, they will learn more and be more persistent. Thus, learners' teachers, peers, the course material, and the curriculum all play an essential role in motivating them (Papi, 2010). Therefore, EFL teachers may use different teaching strategies to give their learners a good learning experience and improve their language proficiency.

Motivation from a Complex Dynamic Systems Perspective is a complex system. The long-held theories of finding relationships among different variables have changed to a more holistic approach about SLA, and the new dynamic system takes into account several elements in specific situations (Dörnyei et al., 2014). The new approach was, in fact, the integration of different factors. In the past, motivation was seen as an ID (Individual Differences) framework; however, Dörnyei (2009) argues that motivation, cognition, and affect work as an organic whole and cannot be separated from one another. Hence, it is impossible to divide the complex system of motivation into parts to study it (Byrne \& Callaghan, 2013). According to Dörnyei et al. (2014), since social sciences deal with human behavior, L2 researchers cannot see motivation in different segregated parts. Therefore, different factors of motivation were blended into a single system.

On the one hand, many researchers welcomed the dynamic system, saying that they would be able to capture the full picture of a multi-dynamic SLA process (Dörnyei et al., 2014). Nevertheless, on the other hand, Dörnyei (2009) asks some crucial questions about the new dynamic system of motivation; (i) if the process is non-linear, how will the researchers make any predictions? (ii) If all the factors are intertwined, then how will the parts be studied while being disconnected? (iii) Is there any alternative to the long relied quantitative research that claims to use precise statistical procedures? It should also be noted here that there are a few researchers who have so far conducted research studies using the new dynamic system, and the majority of them are still using the traditional linear approach (Dörnyei et al., 2014).

\section{Discussion}

After passing through several evolutionary phases, motivation has been divided into different types and associated with different knowledge fields. On the one hand, it is not possible to investigate the motivation construct as a whole; on the other hand, it is difficult for researchers to consider all its types and variables while carrying out a research study. Context, learners' proficiency, and language status are some of the many factors that researchers need to consider before embarking on any research project on motivation.

Individual differences cannot be ignored while studying motivation. Thus viewed, it makes motivation an even harder phenomenon to study or bring in research focus. Learners from different cultures may have different characteristics; therefore, home language, culture, and nationality may influence investigatory variables (Babaee, 2012). Therefore, the motivation construct may continue to be 
complicated but essential at the same time. It will be difficult to challenge the pivotal position of this important construct in second language learning despite its complex nature.

It is crucial to know more about second language learning motivation and classroom motivation for impressively operative educational policy and institutional reforms. Undoubtedly, the complex dynamic system gave a comprehensive view of motivation, but it has also been noticed that the construct cannot be investigated holistically. Therefore, researchers and practitioners need to investigate parts to reach an all-embracing explanation of the concept. All things said and done, motivation is and will remain a complex construct. More in-depth, holistic, and more comprehensive investigations may help us understand the phenomenon.

\section{Conclusion}

This research has opened many questions that urge the need for further investigation and research. The study on the complexity of motivation, focusing on its classification and evolution, is an intriguing one that could be usefully explored in further research. More information on the types and evolution of motivation would help us establish a higher degree of accuracy. A greater focus on second language learning motivation could produce interesting findings that account for learners' needs, likes, and dislikes.

To conclude, the domain of motivation in English Language Teaching and English Language Learning is a desirable research area. With a robust type of empirical evidence resulting from rigorous research for various motivational constructs, researchers can explain variance in school performance over and above intelligence, prior achievement, and age group of the learners. In this regard, the holistic approach is crucial as without including the latter constructs, we might overestimate the importance of motivation for achievement (Steinmayr, Weidinger, Schwinger, \& Spinath, 2019). It will not suffice to provide evidence that students' achievement motivation is incrementally valid in predicting the students' academic achievement. Their intelligence or prior achievement or keeping in mind their age-group would push all the stakeholders - educational administrators, teachers, policymakers, and syllabus designers to design and plan appropriate interventions to improve students' school-related academic motivation.

\section{References}

Babaee, N. (2012). Motivation in learning English as a second language: A literature review. Canadian Journal for New Scholars in Education, 4(1), 1-7.

Brander, A. (2013). Developing language learners with Dörnyei: a study of learning environments and motivation at a Swedish upper-secondary school. (Unpublished Master's thesis). University of Högskolan, Sweden.

Byrne, D., \& Callaghan, G. (2013). Complexity theory and the social sciences: The state of the art. Abingdon: Routledge.

Colak, A. (2008). Attitudes, motivation, and study habits of English language learners: The case of Başkent university second-year students.

Deci, E. L, \& Ryan, R. M (1985). Intrinsic Motivation and Self-Determination in Human Behavior. New

York: Plenum.

Dornyei, Z. (2005). The psychology of the language learner: Individual differences in second language acquisition. New Jersey: Mahwah: Lawrence Erlbaum Associates.

Dörnyei, Z. (1994). Motivation and motivating in the foreign language classroom. The modern language journal, 78(3), 273-284.

Dörnyei, Z. (2003). Attitudes, orientations, and motivations in language learning: Advances in theory, research, and applications. Language learning, 53(S1), 3-32.

Dörnyei, Z. (2009). The psychology of second language acquisition. Oxford: Oxford University Press

Dörnyei, Z., Henry, A., \& MacIntyre, P. D. (Eds.). (2014). Motivational dynamics in language learning. Bristol: Multilingual Matters.

Dörnyei, Z., \& Ushioda, E. (2013). Teaching and researching: Motivation. New York, U.S.A.: Routledge.

Gardner, R. C. (2007). Motivation and second language acquisition. Porta Linguarum, 8, 9-20

Gardner, R. C. (2012). Integrative motivation and global language (English) acquisition in Poland. Studies in Second Language Learning and Teaching, 2(2), 215-226. 
Gollwitzer, P. M, Oettingen, G.(2015) Motivation: History of concept. International Encyclopedia of the Social \& Behavioral Sciences, 15, 936-939.

Guerrero, M. (2015). Motivation in second language learning: A historical overview and its relevance in a public high school in Pasto, Colombia. How, 22(1), 95-106.

Ishtiaq, M., Ali, Z., \& Salem, M. (2015). Effects of Student Teams Achievement Division (STAD) on Motivation of Saudi EFL Adult Learners. International Journal of Language Education and Applied Linguistics, 3, 11-24.

Järvelä, S., Volet, S., \& Järvenoja, H. (2010). Research on motivation in collaborative learning: Moving beyond the cognitive-situative divide and combining individual and social processes. Educational psychologist, 45(1), 15-27.

Keblawi, F. (2009). A review of language learning motivation theories. Jameea. (12), 23-57.

Kozaki, Y., \& Ross, S. J. (2011). Contextual dynamics in foreign language learning motivation. Language Learning, 61(4), 1328-1354.

Kreishan, L. J., \& Al-Dhaimat, Y. (2013). Intrinsic and Extrinsic Motivation, Orientation, and Achievements in L2 of Arab Learners of English, French, and German: A Study from Jordan. International Education Studies, 6(12), 52-63.

Lamb, M. (2007). The impact of the school on EFL learning motivation: An Indonesian case study. Tesol Quarterly, 41(4), 757-780.

Law, Y. K. (2011). The effects of cooperative learning on enhancing Hong Kong fifth graders' achievement goals, autonomous motivation, and reading proficiency. Journal of Research in Reading, 34(4), 402-425.

$\mathrm{Ng}$, C. F., \& Ng, P. K. (2015). A review of the intrinsic and extrinsic motivations of ESL learners. International Journal of Languages, Literature, and Linguistics, 1(2), 98-105.

Noels, K. A. (2003). Learning Spanish as a second language: Learners' orientations and perceptions of their teachers' communication style. In Z. Dörnyei (Ed.), Attitudes, Orientations, and Motivations in Language Learning (pp. 97-136). Oxford: Blackwell.

Öztürk, E. Ö. (2012). Contemporary motivation theories in educational psychology and language learning: An overview. The International Journal of social sciences, 3(1), 33-46.

Pakdel, B. (2013). The historical context of motivation and analysis: theories of individual motivation. International Journal of Humanities and Social Science, 3(18), 240-247.

Papi, M. (2010). The L2 motivational self-system, L2 anxiety, and motivated behavior: A structural equation modeling approach. The system, 38(3), 467-479.

Rahman, S. (2005). Orientation and motivation in English language learning: A study of Bangladesh: Students at the undergraduate level. 7(1), 1-25.

Ryan, R. M., \& Deci, E. L. (2000). Intrinsic and extrinsic motivations: Classic definitions and new directions. Contemporary educational psychology, 25(1), 54-67.

Sabet, M. K., Zafarghandi, A. M., \& Veisy, N. (2015). An Investigation of Efl Learners Linguistics' Intrinsic Motivation Types and Self-Identity Changes. Modern Journal of Language Teaching Methods, 5(4), 765.

Steinmayr, R., Weidinger, A. F., Schwinger, M., \& Spinath, B. (2019). The Importance of Students' Motivation for Their Academic Achievement-Replicating and Extending Previous Findings. Frontiers in psychology, 10, 1-11.

Taguchi, T., Magid, M., \& Papi, M. (2009). The L2 motivational self-system among Japanese, Chinese and Iranian learners of English: A comparative study. In Z. D. E. Ushioda (Ed.), Motivation, language identity, and the L2 self (pp. 66-97).

Tohidi, H., \& Jabbari, M. M. (2012). The effects of motivation in education. Procedia-Social and Behavioral Sciences, 31, 820-824.

Ushioda, E. (2009). A person-in-context relational view of emergent motivation, self, and identity. In D. Ushioda (Ed.), motivation, language identity, and the L2 self (pp. 215-228). Bristol: Multilingual Matters. 
Ushioda, E. (2012). Motivation: L2 learning as a special case? In S. R. M. W. S. Mercer (Ed.), Psychology for language learning: Insights from research, theory, and practice (pp. 58-73). London: Palgrave Macmillan.

Zheng, Y. (2012). Exploring long-term productive vocabulary development in an EFL context: The role of motivation. The system, 40(1), 104-119.

Zhou, H. (2012). Enhancing non-English majors' EFL motivation through cooperative learning. Procedia environmental sciences, 12, 1317-1323. 